\title{
New developments for AATS publications
}

\author{
Richard D. Weisel, MD, Editor, a and Spencer McGrath, BA, MA, Managing Editor ${ }^{\mathrm{b}}$
}

$\overline{\text { From }}{ }^{\mathrm{a}}$ Toronto General Hospital, Toronto, Ontario, Canada; and the ${ }^{\mathrm{b}}$ American Association for Thoracic Surgery, Beverly, Mass.

Disclosures: Authors have nothing to disclose with regard to commercial support.

Address for reprints: Richard D. Weisel, MD, Toronto General Hospital, 101 College St, TMDT 3-704, Toronto,

Ontario M5G 1L7, Canada (E-mail: Richard.weisel@uhn.ca).

J Thorac Cardiovasc Surg 2019;158:820-1

$0022-5223 / \$ 36.00$

Copyright (c) 2019 by The American Association for Thoracic Surgery

https://doi.org/10.1016/j.jtcvs.2019.07.001

The Editors of The Journal of Thoracic and Cardiovascular Surgery (JTCVS) are delighted to review the new developments for JTCVS and the other American Association for Thoracic Surgery (AATS) journals. You are aware of the new colors and fonts that are part of the AATS branding changes. In addition, we have arranged to provide consistent quality and colors to our figures and tables. We hope that you enjoy the new look of JTCVS.

In recent years, JTCVS has seen an increase in the number of submissions, online article downloads, and annual citations. The increase in journal impact can be attributed to the enhanced quality of the articles published. The Journal ensures that all submissions receive at least 3 reviews invited by our Associate Editors, and most articles also receive a scientific and statistical review invited by our Associate Statistical Editors. Most of our articles are also accompanied by a Commentary from an expert in the field - usually one of the reviewers. The quality of the articles and that of the commentaries have contributed to the popularity and influence of the publications. The JTCVS impact factor has steadily increased, reaching an all-time high of 5.261 for 2018 from 4.880 for 2017. JTCVS continues to be ranked 9th of 203 Surgery journals, 24th of 136 journals in the Cardiovascular Systems category, and 8th of 63 journals in the Respiratory System category. In 2018, JTCVS received more than 3 million article downloads-an increase of 30\% from 2017.

The continued increase in the JTCVS impact factor validates our efforts to provide our readers with the most important and highest quality content available. This achievement was made possible by dedication of our reviewers (clinical and statistical), our editors, and the AATS journal publications team. We thank them all for their efforts to provide surgeons with the information they want and the quality they appreciate.

In 2018, JTCVS received more than 3000 submissions, and original manuscripts and AATS and Western Thoracic Surgical Association meeting papers increased 21\% from 2017. We are on track to receive a record number of submissions again this year. In response to the rise in submissions, we have significantly expanded the editorial team to help us

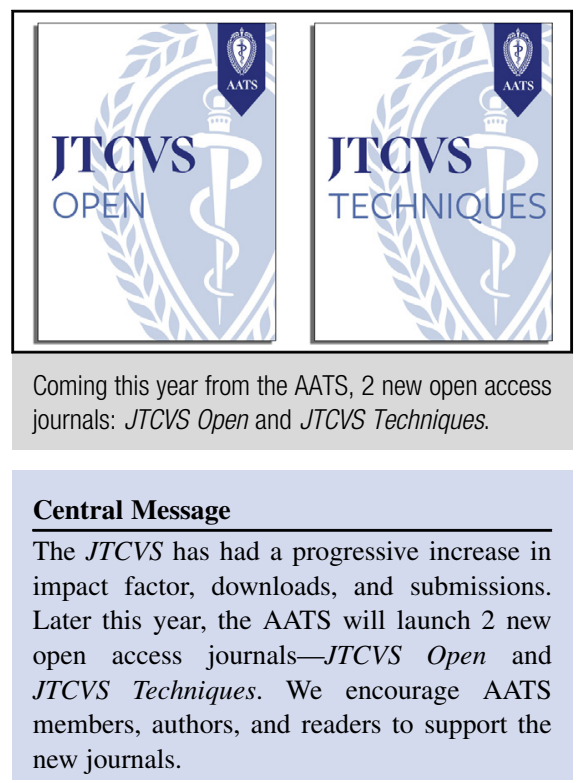

meet the increased demands while maintaining high-quality peer review and short turn-around times. We are proud that the average time to first decision last year was 21 days.

What should we do with the increasing number of outstanding submissions? Five years ago, we began offering authors the option of publication in Seminars in Thoracic and Cardiovascular Surgery (Seminars). These articles were fully reviewed and revised, as suggested by the Journal clinical and statistical editors. The articles were considered to have interest and value for our community, but they did not achieve the impact required for the Journal. The option of transferring a JTCVS submissions to Seminars has been extremely successful. Since 2014, we have transferred nearly 250 manuscripts to Seminars, and now $85 \%$ of authors who are offered transfer to Seminars agree. As a result, the impact of Seminars has increased dramatically, with downloads and citations equivalent to other thoracic surgical journals. In addition, Seminars publishes roundtable discussions and multiple invited reviews.

Later this year, AATS will launch 2 new open access journals, JTCVS Open and JTCVS Techniques, to provide authors with additional options to publish high-quality information of importance to thoracic and cardiovascular surgeons. We plan to follow the same process that we have used successfully with Seminars. Authors who have submitted to JTCVS will be offered transfer if the manuscript has insufficient priority for publication in JTCVS. The articles will be fully reviewed and revised, as suggested by the clinical and statistical reviewers and editors of the Journal. If a manuscript has value but is not 
anticipated to have sufficient impact for the Journal, authors will be given the option to transfer it to JTCVS Open or JTCVS Techniques.

Authors will initially have 2 transfer options for most full manuscripts, either Seminars or JTCVS Open. Seminars is a subscription journal, and the published articles are therefore not immediately available for worldwide distribution because of the pay wall; however, most AATS members have subscriptions to Seminars. The open access journals will request that the authors pay a fee for publication after a manuscript has been accepted, but published articles will be immediately available to all readers worldwide without restrictions. The other advantage of our new open access journals is that they are owned by the AATS. This arrangement will facilitate the distribution of the content from all AATS journals to our community.

Like JTCVS, JTCVS Open will have articles on the latest developments in adult cardiac surgery, congenital cardiac conditions and repair, thoracic diseases and procedures, heart and lung transplantation, mechanical circulatory support, and perioperative management. JTCVS Techniques will provide a venue to publish high-quality case reports, innovative surgical techniques, and cardiothoracic images with video and multimedia formats. Videos will be an important component in JTCVS Techniques. The online, open access format of that journal provides an innovative digital platform to demonstrate techniques and report outcomes of new surgical interventions. During the next year, nearly all case reports, surgical techniques, and imaging articles will be transferred from the Journal to JTCVS Techniques; however, JTCVS readers will be given single-click, immediate access to all the articles published in JTCVS Techniques and JTCVS Open from either the online version or the print version (with a QR code). In addition, AATS online will provide readers access to the featured material in each subspecialty from any of the AATS journals.

We hope that AATS members and all our authors and readers will support the new publications when they begin accepting submissions later this year. 